\title{
Impact of the SARS-CoV-2 pandemic and first lockdown on pregnancy monitoring in France: the COVIMATER cross-sectional study
}

\author{
Alexandra Doncarli ${ }^{1{ }^{*}}$, Lucia Araujo-Chaveron ${ }^{1 \dagger}{ }^{\dagger}$, Catherine Crenn-Hebert ${ }^{2}$, Virginie Demiguel ${ }^{1}$, \\ Julie Boudet-Berquier' ${ }^{1}$, Yaya Barry' ${ }^{1}$ Maria-Eugênia Gomes Do Espirito Santo', Andrea Guajardo-Villar³, \\ Claudie Menguy ${ }^{1}$, Anouk Tabai ${ }^{4}$, Karine Wyndels ${ }^{5}$, Alexandra Benachi ${ }^{6,7}$ and Nolwenn Regnault ${ }^{1}$
}

\begin{abstract}
Background: In the context of the severe acute respiratory syndrome coronavirus 2 (SARS-CoV-2) pandemic, consultations and pregnancy monitoring examinations had to be reorganised urgently. In addition, women themselves may have postponed or cancelled their medical monitoring for organisational reasons, for fear of contracting the disease caused by SARS-CoV-2 (COVID-19) or for other reasons of their own. Delayed care can have deleterious consequences for both the mother and the child. Our objective was therefore to study the impact of the SARS-CoV-2 pandemic and the first lockdown in France on voluntary changes by pregnant women in the medical monitoring of their pregnancy and the associated factors.
\end{abstract}

Methods: A cross-sectional study was conducted in July 2020 using a web-questionnaire completed by 500 adult (>18years old) pregnant women during the first French lockdown (March-May 2020). A robust variance Poisson regression model was used to estimate adjusted prevalence ratios (aPRs).

Results: Almost one women of five (23.4\%) reported having voluntarily postponed or foregone at least one consultation or pregnancy check-up during the lockdown. Women who were professionally inactive (aPR $=1.98, \mathrm{Cl} 95 \%[1.24-$ 3.16]), who had experienced serious disputes or violence during the lockdown (1.47, [1.00-2.16]), who felt they received little or no support (1.71, [1.07-2.71]), and those who changed health professionals during the lockdown (1.57, [1.04-2.36]) were all more likely to have voluntarily changed their pregnancy monitoring. Higher level of worry about the pandemic was associated with a lower probability of voluntarily changing pregnancy monitoring $(0.66$, [0.46-0.96]).

Conclusions: Our results can guide prevention and support policies for pregnant women in the current and future pandemics.

Keywords: Pregnant women, SARS-CoV-2, Lockdown, Pregnancy monitoring

*Correspondence: alexandra.doncarli@santepubliquefrance.fr ${ }^{\dagger}$ Alexandra Doncarli and Lucia Araujo-Chaveron contributed equally to this work.

${ }^{1}$ Santé publique France, French national public health agency, Non-Communicable Diseases and Trauma Division, Perinatology, Early childhood and Mental Health Unit, 14, rue du Val d'Osne, F-94415 Saint-Maurice, France

Full list of author information is available at the end of the article

\section{Background}

Data from previous coronavirus outbreaks in 2002 and 2013 showed that pregnancy was a risk factor for severe forms of associated respiratory diseases. More specifically, SARS-CoV-1 and Middle East respiratory syndrome-related coronavirus were associated with significant acute respiratory distress syndrome $[1,2]$. This 
fact, together with recommendations of learned societies $[3,4]$, prompted several countries, including France, to declare in March/April 2020 that pregnant women should be considered a population at greater risk of severe forms of COVID-19, the disease caused by SARS-CoV-2 [5-9]. In the absence of vaccines and effective pharmaceutical treatments at that time, most governments decided to reduce the spread of the virus by implementing strict lockdowns of their entire population for several months. These actions together with to the increased influx of patients suffering from COVID-19 brought about major changes in the organisation of health systems [10-12], including the organisation of hospital gynaecological departments [10-13]. In the United States (U.S.) a longitudinal study reported a decrease of $40 \%$ in on-site abortion during the first trimester of pregnancy between February and June 2020. In addition, a decrease in onsite consultations for abortion follow-up was observed, prompting an increase in teleconsultations and medical abortion at home [13]. Another U.S. study, conducted between mid-March and mid-May 2020 showed that nearly one-third of pregnancy monitoring visits were modified, cancelled or rescheduled [14]. In France, a longitudinal study on the surgical management of gynaecological cancers reported a change in medical management for $27 \%$ of its participants, including $23.2 \%$ for whom surgery was either postponed or cancelled due to the influx of patients infected with SARS-CoV-2 during the first lockdown [15], which took place between 16 March and 11 May 2020.

With regard to pregnancy, monitoring consultations were initially deprogrammed by French health professionals before official guidelines recommended that follow-up be maintained and reorganised $[3,12,16,17]$. The French healthcare system adapted very quickly to the crisis, offering $100 \%$ reimbursed tailored teleconsultation (video and telephone-based consultations) to pregnant women [18]. Maternity wards and private offices also changed pregnancy monitoring practices. More specifically, partners were not allowed to be present during consultations, obstetric examinations or during hospitalization for childbirth, except under certain conditions [19]. Only partners were allowed to visit after childbirth [19].

In addition to the reorganisation of the health sector, some women voluntarily (i.e., spontaneously) modified their medical monitoring for different reasons, for example organisational scheduling [20].

Any postponement or foregoing of consultations or examinations in the context of pregnancy is of particular concern for the health of both the mother and child, as screening must be performed within specific time windows [21]. More specifically, failure to monitor foetal weight gain, screen for gestational diabetes and hypertension, has deleterious consequences for the newborn [22-24].

In the context of the SARS-CoV-2 pandemic, it is essential that the health management of pregnant women be continually adapted to best meet the changing needs in this dynamic context. To do this, it is necessary to understand the reasons why pregnant women voluntarily change their pregnancy monitoring.

Our objective was to study i) the effects of the SARS$\mathrm{CoV}-2$ pandemic and France's first associated lockdown on the frequency of voluntary changes in pregnancy monitoring by women during the country's first lockdown, and ii) associated factors.

\section{Methods}

\section{Study population (Covimater)}

Our sample comprised 500 adult women who were pregnant during the first lockdown in France (17 March - 11 May 2020). Participants were 18 years old and over and residents in metropolitan France. We excluded two groups of women who were pregnant during the lockdown but with limited exposure to it: those who delivered in the two first weeks of the lockdown and those whose first week of gestation began during the last two weeks of the lockdown (deducted from the expected date of delivery reported by the women).

\section{Survey methodology}

At our request, a service provider (BVA group) interviewed its unpaid pre-pandemic panel of 15,000 future parents or parents of children under 3 years of age in order to create a pseudonymised non-probability sample of 500 adult pregnant women who met the inclusion criteria and volunteered to participate in our survey. Covimater used quotas sampling, whereby the study sample is assigned a structure similar to that of the target population (i.e., all pregnant women) in order to tend towards representativeness. The population of parents of children under one year old - as per the National Institute of Statistics and Economic Studies 2016 census - was used to set the quotas [25]. Indeed, the latter was a good proxy for our target population of pregnant women in France. Only the quotas for mothers were used to calculate weightings using Newton's algorithm [26]. Specifically, these quotas comprised age group, socio-professional category (SPC), region of residence, size of urban area, and parity. Eligible women were invited to answer a webbased questionnaire between 6 and 20 July 2020, which collected socio-demographic/economic data, pandemic and lockdown-related data, participants' perceptions of the pandemic, data on their pregnancy and health, and on pregnancy monitoring during the first lockdown (see 
Additional file 1). We compared our sample to another data source (the National Medical and Administrative Database) in order to validate its representativeness. No significant difference in available data for age group, region of residence or parity was observed between women participating in Covimater and the whole population of women in France who gave birth in a hospital maternity ward (i.e., 99\% of French pregnant women population [27]). Our study shows, with a power of $99 \%$, a difference of at least $20 \%$ concerning the variable of interest (see definition below) between two subgroups of balanced/unbalanced women.

\section{Changes in pregnancy monitoring at the initiative of pregnant women}

For the present study, women who voluntarily changed their pregnancy monitoring during the lockdown were defined as those who reported at least one of the following in the questionnaire: (i) foregoing pregnancy examinations, (ii) voluntarily postponing or cancelling pregnancy consultations, (iii) delaying the start of monitoring (i.e., not starting monitoring despite a gestational age of over 15 weeks) [27].

The reasons for changes in pregnancy monitoring were explored through 13 binary questionnaire items covering different themes (lockdown, SARS-CoV-2 infection, and organisational problems, specifically personal and healthcare-based).

\section{Covariates}

Explanatory variables were divided into five main themes:

\section{Demographic and socio-economic}

Age, socio-professional category (SPC) reduced into $\mathrm{SPC}+$ (self-employed women, managers, intermediate professions), SPC- (employees, blue-collar workers) and Inactive (students and other professionally inactives), education level (equal to or higher than secondary school diploma, lower than secondary school diploma), perceived financial situation (comfortable, just getting by, difficult to make ends meet).

\section{Pandemic and lockdown-related}

Child(ren) under six years of age (i.e., younger than required school age in France) in the household during the lockdown, SARS-CoV-2 healthcare system severity as reported by the Ministry of Health on 1 May 2020 in their region of residence (coded as green, orange or red, reflecting increased epidemic pressure on the healthcare system) [28], professional workload (did not work, lighter/same than usual, heavier than usual), access to a private/common outdoor space, self-perceived social support (i.e., from family, friends, etc.) (Very good,
Good, Little or none), having experienced serious arguments and/or a climate of violence (Very-often/Often, Sometimes/Rarely, Never), having had COVID-19 type symptoms, family member or friends diagnosed with COVID-19 or had symptoms suggestive of the disease.

\section{Perception of the epidemic}

Participants' perceived general worry about the pandemic situation in France (scale from 0, not at all worried to 10 , very worried). A dichotomous variable was then created with $7 / 10$ as the thresholds corresponding to the average worry observed $(7.0+/-0.1)$.

\section{Pregnancy and health}

Parity, gestational age at the end of lockdown, childbirth (during or after first lockdown), at least one preexisting chronic disease or pregnancy-related pathology, overweight/obesity status before pregnancy (Body Mass Index $\geq 25 \mathrm{~kg} / \mathrm{m}^{2}$ ).

\section{Pregnancy monitoring during first lockdown}

Unsuccessful attempts to have an exchange with healthcare professionals about the course of pregnancy/childbirth during pandemic, change in health professional from the one who usually followed them, teleconsultation (video or telephone) for pregnancy monitoring, absence of partner/person providing support from at least one pregnancy consultation/examination due to pandemic related restrictions, childbirth preparation sessions (video or telephone).

\section{Statistical analysis}

A robust variance Poisson regression model was used to estimate unadjusted and adjusted prevalence ratios (aPR) [29] for voluntary changes in pregnancy monitoring. Factors associated with this outcome which had a $p$-value $<0.20$ in bivariate analysis or which were judged to be clinically relevant based on the literature (gestational age at the time the study questionnaire was completed, gestational age at the end of the lockdown period, parity) were introduced into the multivariate model. When several variables were possibly collinear, the model with the best likelihood score (lowest Bayesian Information Criterion) was selected. Fractional polynomials showed a linear relationship between continuous variables included in the models and the studied prevalence of the outcome. The final model included the variables independently associated with the variable of interest $(p$-value $<0.05)$ after epidemiological reflection and according to the clinical relevance of each variable at each step of the procedure. A manual stepwise descending approach was applied. 
Estimates of aPR, their 95\% confidence intervals (95\% $\mathrm{CI}$ ) and associated $p$-values were presented. As indicated by Zou, PRs are interpreted in the same way as relative risks [30].

All statistical analyses were performed using Stata software $^{\circledR}$ version 14.2 (Stata Corp., College Station, TX, USA).

\section{Results}

\section{Characteristics of women included in Covimater (Table 1)}

The mean age was of the Covimater study sample $(n=500)$ was 31.4 years $(\mathrm{sd}=5.1)$. Four-fifths $(78.1 \%)$ had a secondary school diploma or higher level of education, $36.1 \%$ were classified SPC-, $25.5 \%$ were Inactive, 31.7\% declared they just got by financially, while $19.1 \%$ reported that they could not make ends meet.

From a medical perspective, $42.4 \%$ had overweight or obesity before pregnancy, and $23.7 \%$ had pregnancyrelated pathologies, notably gestational diabetes (12.6\%), preterm labour (5.9\%), and gestational hypertension (1.6\%) (data not shown). Finally, $17.9 \%$ perceived receiving little or no social support during the lockdown, and nearly $28 \%$ experienced serious arguments and/or a climate of violence during the same period.

\section{Pregnancy monitoring during the first lockdown (Table 1)}

A total of $14.9 \%$ of women reported that they had been followed by a professional other than the one who usually followed them, 39.4\% reported that they had teleconsultations, and $91.8 \%$ reported that their partner or a person providing support had not been allowed to attend at least one pregnancy check-up or consultation due to pandemic-related restrictions. In addition, $41 \%$ indicated that they unsuccessfully sought exchanges about the SARS-CoV-2 pandemic and their pregnancy with healthcare professionals.

Of the pregnant women who indicated that they had not started their pregnancy monitoring during the lockdown, the majority (63.7\%) had a gestational age of over 15 weeks, indicating a delay in the management of their pregnancy.

\section{Voluntary changes in pregnancy monitoring}

Just under half of the study sample (48.9\%) reported having at least one consultation or pregnancy check-up postponed or cancelled during the lockdown, whether on their own initiative (23.4\%) and/or the initiative of the hospital and/or a health professional (36.3\%).

The most frequent reasons participants gave for voluntary changes to their pregnancy monitoring were related to the pandemic and lockdown (i.e., fear of being infected with SARS-CoV-2; compliance with restrictions on movement), to personal organisational problems (e.g., caring for other children), and hospital problems (e.g., inability to make an appointment with a health professional) (Fig. 1).

Among women who declared foregoing at least one pregnancy monitoring examination $(n=75)$ as a direct result of the lockdown, almost one-third forewent i) supplementary prescribed or recommended pregnancy monitoring examinations/consultations (31.1\%, CI95\%[19.8-45.2]) or ii) Trisomy 21 screening (29.2\% [17.1-45.1] regardless of gestational age (data not shown); $17.4 \%$ [7.9-33.9] before 16 gestational weeks), iii) one in four reported not having monthly toxoplasmosis serology (25.7\%, [14.8-41] (Fig. 2).

After adjusting for age, gestational age and parity during the first lockdown, being inactive $(\mathrm{RPa}=1.98$, CI95\%[1.24-3.16]), having experienced violence (1.47, [1.00-2.16]), having felt little or no support (1.70, [1.07$2.71])$, and having changed healthcare professional (1.57, [1.04-2.36]) were all independently and significantly associated with a voluntary change in pregnancy monitoring. Conversely, higher level of worry about the pandemic was inversely associated with voluntary change in pregnancy monitoring $(0.66$ [0.46-0.96]) (Table 2).

\section{Discussion}

Just under half the study sample (48.9\%) reported at least one consultation or pregnancy check-up being postponed or cancelled during the first lockdown, whether on their own initiative (23.4\%) and/or the initiative of the hospital and/or that of a health professional (36.3\%).

Women who i) were inactive, ii) perceived received little or no social support, iii) experienced violence, and whose iv) healthcare professional changed during the first lockdown, were all significantly more likely to voluntarily change their pregnancy monitoring. Conversely, worry about the pandemic was inversely associated with changing pregnancy monitoring.

Covimater's results show an association between violence and a voluntary change in pregnancy monitoring. The percentage of pregnant women who reported experiencing violence or serious arguments during the first lockdown was high (28.1\%), but significantly lower than that obtained for women of childbearing age (18-49years) in CoviPrev, a French general populationbased repeated cross-sectional study which used the same methodology as Covimater and conducted datacollection waves at the same time (CoviPrev study, 28.1\% vs. $32.9 \%, p=0.03$ ) [31]. This result is in line with several studies suggesting that the prevalence of violence on women during pregnancy is no higher than in other situations. However, there is no international consensus about whether the risk of violence is higher in pregnant women than in women who are not pregnant [32-34]. 
Table 1 Description of pregnant women who participated in the Covimater survey $(n=500)$, France (July 2020)

\begin{tabular}{|c|c|c|c|}
\hline & \multicolumn{2}{|c|}{$\mathrm{N}(\%)^{*}$} & $95 \% \mathrm{Cl}^{* *}$ \\
\hline \multicolumn{4}{|l|}{ Demographic and socio-economic characteristics } \\
\hline \multicolumn{4}{|l|}{ Age (in years) } \\
\hline $18-24$ & 53 & $(10.7)$ & $7.4-15.2$ \\
\hline $25-34$ & 323 & $(64.6)$ & $59.7-69.2$ \\
\hline $35-49$ & 124 & $(24.7)$ & $21.1-28.8$ \\
\hline \multicolumn{4}{|l|}{ Socio-professional category (SPC) ${ }^{\mathrm{a}}$} \\
\hline $\mathrm{SPC}+$ & 192 & $(38.4)$ & $33.9-43.2$ \\
\hline SPC - & 180 & $(36.1)$ & $31.8-40.6$ \\
\hline Inactive & 128 & $(25.5)$ & $20.5-31.2$ \\
\hline \multicolumn{4}{|l|}{ Educational level } \\
\hline Equal to or higher than secondary school diploma & 391 & $(78.1)$ & $73.6-82.1$ \\
\hline Lower than secondary school diploma & 109 & $(21.9)$ & $17.9-26.4$ \\
\hline \multicolumn{4}{|l|}{ Perceived financial situation } \\
\hline Comfortable & 246 & $(49.2)$ & $44.2-54.2$ \\
\hline Just getting by & 159 & $(31.7)$ & $27.2-36.6$ \\
\hline Difficult to make ends meet & 95 & $(19.1)$ & $15.2-23.7$ \\
\hline \multicolumn{4}{|l|}{ Pandemic and lockdown related variables } \\
\hline Child(ren) under 6 years of age in the household during the lockdown & 234 & $(46.8)$ & $41.8-51.8$ \\
\hline \multicolumn{4}{|l|}{ SARS-CoV-2 healthcare system severity (colour-coded) for the region of residence ${ }^{b}$} \\
\hline Green zone & 127 & $(25.4)$ & $21.1-30.2$ \\
\hline Orange zone & 150 & $(30.0)$ & 25.7-34.7 \\
\hline Red zone & 223 & $(44.6)$ & $39.7-49.6$ \\
\hline \multicolumn{4}{|l|}{ Professional workload } \\
\hline Did not work & 351 & $(70.1)$ & $65.7-74.2$ \\
\hline Lighter or same as usual & 85 & $(17.1)$ & $14.0-20.7$ \\
\hline Heavier than usual & 64 & $(12.8)$ & $10.1-16.0$ \\
\hline \multicolumn{4}{|l|}{ Self-perceived social support } \\
\hline Very good & 180 & $(36.0)$ & $31.3-40.9$ \\
\hline Good & 231 & $(46.1)$ & $41.2-51.1$ \\
\hline Little or none & 89 & $(17.9)$ & $14.5-21.8$ \\
\hline \multicolumn{4}{|l|}{ Serious disputes or violence } \\
\hline Very-often / Often & 11 & $(2.3)$ & $1.1-4.6$ \\
\hline Sometimes / Rarely & 129 & $(25.8)$ & $21.7-30.4$ \\
\hline Never & 360 & $(71.9)$ & $67.2-76.2$ \\
\hline Having had COVID-19 type symptoms & 92 & $(18.4)$ & $14.9-22.6$ \\
\hline Family member or friends diagnosed with COVID-19 or had symptoms suggestive of the disease & 171 & $(34.2)$ & $29.7-39.0$ \\
\hline \multicolumn{4}{|l|}{ Perception of the pandemic } \\
\hline General worry score for the SARS-CoV-2 pandemic ( $\max .10 ; n=485 ;$ No documented data $=15$ ) $>7 / 10$ & 234 & $(48.3)$ & $43.3-53.3$ \\
\hline \multicolumn{4}{|l|}{ Pregnancy and health } \\
\hline Primiparous & 203 & $(40.6)$ & $35.8-45.6$ \\
\hline \multicolumn{4}{|l|}{ Gestational age (weeks) at the end of first lockdown ${ }^{c}$} \\
\hline$<10$ & 34 & $(6.8)$ & $4.7-9.8$ \\
\hline $10-20$ & 177 & $(35.4)$ & $30.8-40.3$ \\
\hline $20-30$ & 180 & $(36.1)$ & $31.4-41.0$ \\
\hline $30-40$ & 77 & $(15.4)$ & $12.1-19.4$ \\
\hline$>40$ & 32 & $(6.3)$ & $4.3-9.2$ \\
\hline \multicolumn{4}{|l|}{ Childbirth } \\
\hline During lockdown & 34 & $(6.8)$ & $4.7-9.8$ \\
\hline After lockdown & 466 & $(93.2)$ & $90.2-95.2$ \\
\hline
\end{tabular}


Table 1 (continued)

\begin{tabular}{|c|c|c|c|}
\hline \multirow[b]{2}{*}{ Pre-existing chronic disease $(s)^{d}$} & \multicolumn{2}{|c|}{$\mathbf{N}(\%)^{*}$} & \multirow{2}{*}{$\frac{\mathbf{9 5} \% \mathrm{Cl}^{* *}}{25.8-35.1}$} \\
\hline & 152 & (30.3) & \\
\hline Overweight / Obesity & 212 & (42.4) & $37.5-47.4$ \\
\hline Pregnancy-related pathology(ies $)^{f}$ & 119 & (23.7) & $19.9-28.0$ \\
\hline \multicolumn{4}{|l|}{ Pregnancy monitoring during first lockdown } \\
\hline $\begin{array}{l}\text { Having an unsuccessful attempts to exchange with health professionals about course of pregnancy/child- } \\
\text { birth during pandemic }\end{array}$ & 205 & $(41.0)$ & $36.1-46.1$ \\
\hline Change of health professional than the referring professional ${ }^{9}$ & 74 & $(14.9)$ & $11.7-18.8$ \\
\hline Teleconsultations (video or telephone) for pregnancy monitoring & 197 & (39.4) & $34.6-44.4$ \\
\hline Absence of partner/person providing support from a consultation/examination & 459 & $(91.8)$ & $88.8-94.1$ \\
\hline Childbirth preparation sessions (video or telephone) & 76 & $(15.2)$ & $12.0-19.1$ \\
\hline Modification of pregnancy monitoring at the initiative of a health professional ${ }^{\text {h }}$ & 182 & $(36.3)$ & $31.6-41.3$ \\
\hline Modification of pregnancy monitoring at the initiative of the women ${ }^{i}$ & 117 & (23.4) & $18.8-27.7$ \\
\hline
\end{tabular}

* Weighted and rounded values using Newton's algorithm [26]

** $95 \%$ Confidence Interval

${ }^{a}$ Women on maternity leave and unemployed women were classified according to their current SPC category or their most recent category prior to ending work, respectively.

${ }^{b}$ Estimated by the Ministry of Health on 1 May 2020 on the basis of two variables: i) Virus circulation level (i.e., percentage of emergency room admissions for suspected COVID-19) and ii) Strain on hospital intensive care unit capacity (i.e.,occupancy rate of intensive care beds by patients with COVID-19), coded as green, orange or red, reflecting increased epidemic pressure on the healthcare system [28]

c At the end of the first lockdown (11 May 2020) or at the date of childbirth if women gave birth during lockdown

d Diabetes, Overweight/Obesity status before pregnancy, High Blood Pressure, Asthma, Cardiac condition, Autoimmune disease, mental illness, etc.

e Body Mass Index $\geq 25 \mathrm{~kg} / \mathrm{m} 2$

${ }^{f}$ Gestational diabetes, pre-eclampsia, preterm labour, gestational hypertension, etc.

${ }^{g}$ performed in a sub-group of pregnant women having start monitoring

${ }^{\mathrm{h}}$ Modification was to postpone/cancel pregnancy monitoring

i Modification was to postpone/forego /not start monitoring despite a gestational age of 15 weeks (see definition of the variable of interest in Methods section)

Violence during pregnancy not only negatively impacts mothers' health, but also that of their unborn children. It also impacts success of antenatal care. Furthermore, violence is significantly associated with an increased risk of obstetrical complications [35-37]. In terms of antenatal care, a survey held by the World Health Organisation in Tanzania studying domestic violence on women showed that it was significantly associated with fewer consultations for antenatal care because partners prevented or discouraged women from having them [34]. Efforts to detect violence against pregnant women at an early stage must be continued in order to prevent its harmful impact on health.

In Covimater, perceiving little or no support during the lockdown was associated with voluntary change in pregnancy monitoring. These results reflect findings from the 2010 French National Perinatal Survey (NPS), where women who declared having no social support were significantly more likely to forego care [38]. The perception of receiving little support may have been accentuated by the fact that during the first lockdown, in many maternity hospitals and private practices in France, neither partners nor people providing support to pregnant women were allowed to be present at consultations, obstetrical examinations, and hospitalisation for childbirth, except under certain conditions [19]. Only partners were allowed to visit after childbirth.

In our analyses, a change in health professional during the lockdown was associated with a higher likelihood of voluntarily postponing or foregoing pregnancy monitoring. As reported in several studies showing the importance of the patient/caregiver relationship in medical follow-up (in terms of treatment adherence, health examinations, etc.), it seems fundamental to ensure that the monitoring of pregnant women is as personalized as possible in the context of an ongoing pandemic.

In our study, women who had a higher worry score about the pandemic were less likely to change their pregnancy monitoring. This result suggests the need to communicate with pregnant women with a double objective: i) to avoid any increase in existing worry about the pandemic, and ii) to foster their adherence to health authorities' recommendations concerning uninterrupted pregnancy monitoring. To ensure the quality and regular updating of information received by pregnant women, it is important to involve health care providers so that they can inform or direct their patients to reliable and responsive sources of information [39]. French laws for patients' 


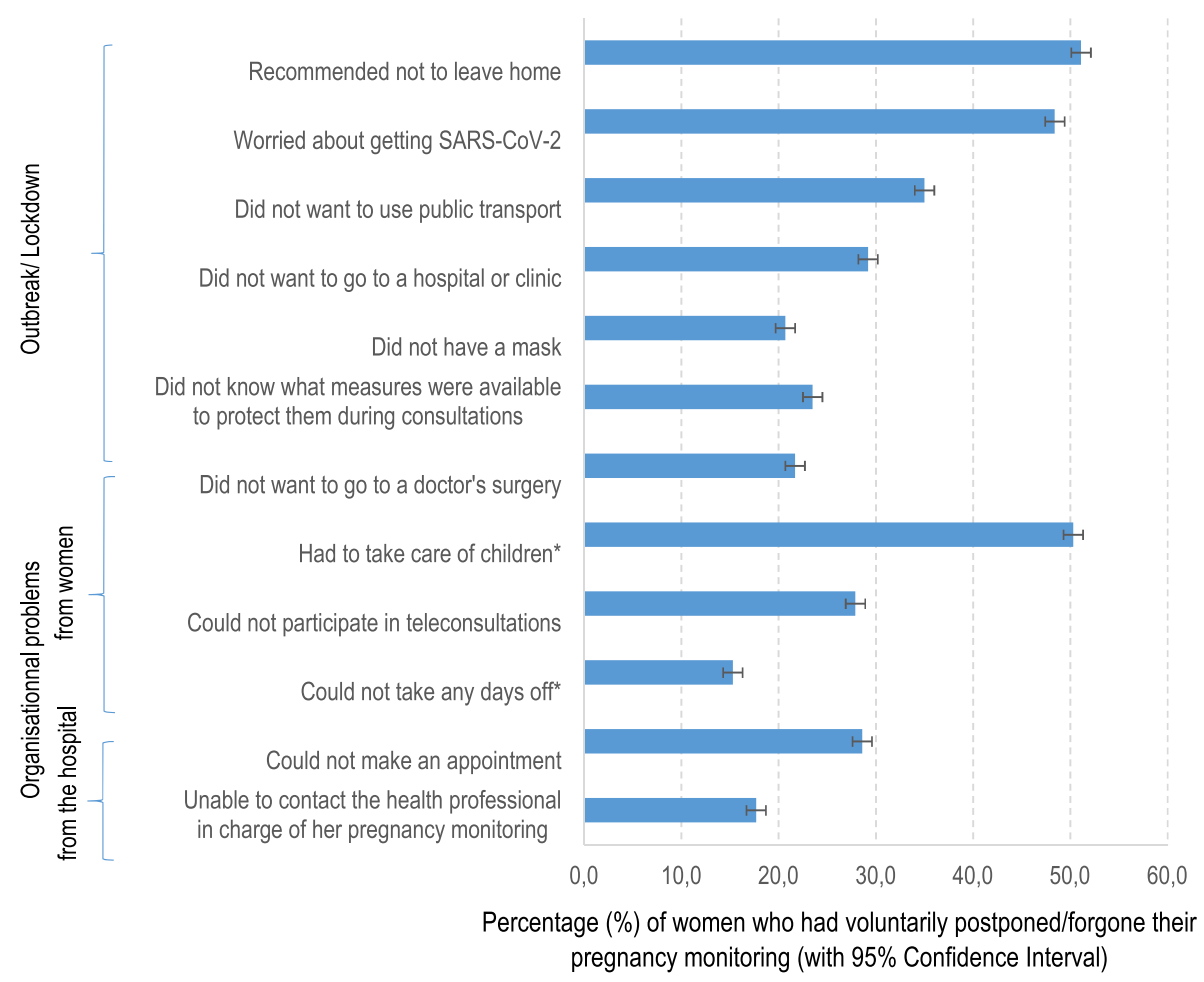

*Analysis carried out in a subgroup of women (who had children or who were working during the lockdown).

$\$$ : Postponing/foregoing/not starting monitoring despite a gestational age of 15 weeks (see definition of the variable of interest in Methods section).

\#: No documented data for 10 pregnant women who had not start monitoring despite a gestational age of 15 weeks.

Fig. 1 Reasons given by pregnant women" to explain a voluntarily change ${ }^{\ddagger}$ in pregnancy monitoring during lockdown

rights and the Public Health Code stipulate that patients have the right to have access to information [40] and that doctors must inform them of advances in science according to their needs. Access to reliable information is therefore an essential element in effective patient follow-up.

Finally, in line with Ancelot et al's findings in the NPS study in France in 2010 [38], having a chronic illnesses or a pregnancy-related illness was not significantly associated with a voluntary change in pregnancy monitoring in Covimater. Furthermore, participants in Covimater with a deteriorated psychological state during the first lockdown were not more likely to change their pregnancy monitoring than those with no such condition $(p$-value $=0.89)$.

In addition to characterising women with a higher prevalence of modifying their pregnancy monitoring during the first COVID-19-related lockdown in France, our study also aimed to stress the declared reasons for these voluntary postponements or waiving of care. In addition to those related to the pandemic (i.e., fear of being infected by SARS-CoV-2, compliance with restrictions on movement), some of these self-perceived reasons were organisational in nature, whether related to healthcare provision, or personal organisation problems linked to the pandemic. In Covimater, 28.6, 17.7 and $15.3 \%$ of women who voluntarily changed their pregnancy monitoring declared, respectively, that they had not managed to make an appointment, that they had not been able to contact the health professional who usually followed them, or that it had been impossible for them to take days off work to attend their pregnancy appointments during lockdown. Despite French authorities' recommendations to promote video and telephone-based consultations when possible outside of the three compulsory ultrasounds requiring physical presence, a relatively large proportion of women who modified their pregnancy monitoring did it because they were unable to contact healthcare structures. In terms of personal organisation of healthcare schedules, discussions are currently underway at the national level to provided current and future parents with greater flexibility to better reconcile their professional and parenthood [41]. 


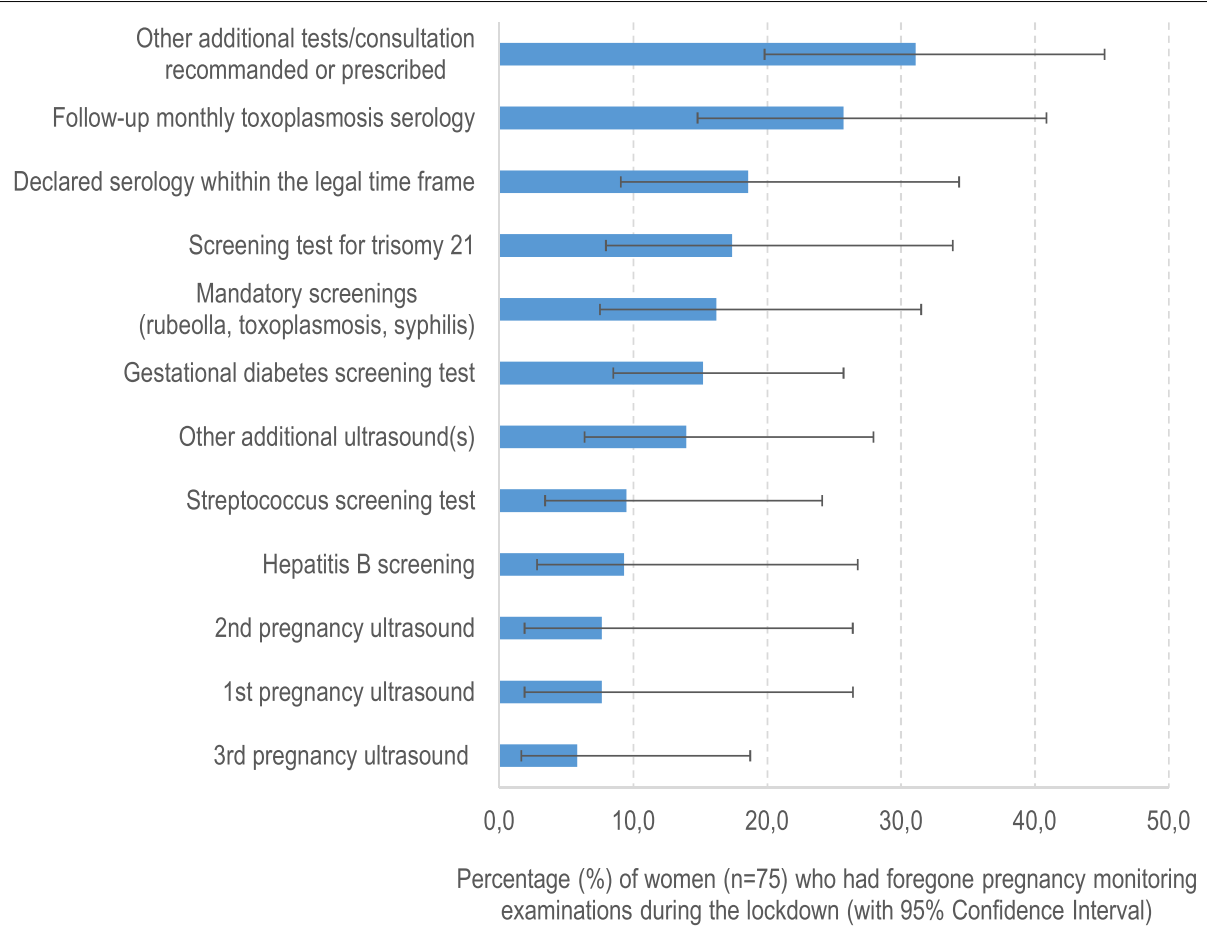

Fig. 2 Foregoing of pregnancy monitoring examinations during the lockdown, Covimater survey; $(n=75)$, metropolitan France, 2020

\section{Strengths and limitations}

To the best of our knowledge, Covimater was the first national study in France to explore the experiences and behaviours of pregnant women during the SARS-CoV-2 pandemic. It used the same methodology as another study conducted in France at the same time on the general population entitled CoviPrev. This choice was made to ensure comparison with women of childbearing age. Unlike studies from other countries which mostly focused on the third trimester of pregnancy during the current pandemic, Covimater included women with different gestational ages. In Covimater, although some groups compared were unbalanced in size (with consequently reduced power), this did not prevent the identification of significant associations with the variable of interest.

Covimater had some limitations. First, the use of a panel and quota sampling could imply a bias in the pregnant women included for the survey. However, there was no alternative method available that would allow for the study to take place within a short time after the lockdown and thus avoid a significant recall bias. The further away the lockdown was, the more difficult it would have been to collect reliable information from women about their behaviour and feelings during the period.. Consequently, greater caution is required when interpreting the statistical inference than would be needed for random sample studies. Second, sampling bias could explain the overestimation of the percentage of pregnant women with pre-existing chronic diseases or obesity. Third, as the study questionnaire was selfadministered, there is always the risk that respondents misunderstood or misinterpreted questions and a risk of recall biases or potential social desirability. Thus, the declarative nature of our survey may have led women to indicate changes in their pregnancy monitoring that were in fact a consequence of underlying situations (social desirability bias, self-complacency biais, memory bias, etc.), which could not be assessed. However, there is no reason to suppose that either of these biases should be limited to the particular sub-group of pregnant women who had postponed/forgone their pregnancy monitoring.

\section{Conclusions}

The results of this study highlighted the importance of defining strategies to prevent voluntary changes in pregnancy monitoring among women in difficult social situations (isolation, violence), which may be accentuated by the ongoing COVID-19 pandemic. In addition, it is necessary to increase access to teleconsultations and provider-patient communication channels during 
Table 2 Factors associated with the prevalence of voluntary changes ${ }^{a}$ in women's pregnancy monitoring in France, (07/2020)

\begin{tabular}{|c|c|c|c|c|c|c|}
\hline \multirow[b]{3}{*}{ Age (in years) } & \multirow{2}{*}{\multicolumn{2}{|c|}{ Obs. $(\mathrm{n} \%)^{*}$}} & \multicolumn{4}{|c|}{$\begin{array}{l}\text { Voluntary changes in medical monitoring of pregnancy initiated by } \\
\text { pregnant women }(n=117)^{\mathrm{a}}\end{array}$} \\
\hline & & & \multicolumn{2}{|c|}{ Yes $(\mathrm{n} \%)^{*}$} & \multirow{2}{*}{$\begin{array}{l}\text { Adjusted PR [95\% Cl] } \\
0.99[0.96-1.03]\end{array}$} & \multirow{2}{*}{$\frac{p \text {-value }}{0.77}$} \\
\hline & 31.4 & (5.1) & 32 & (5.6) & & \\
\hline \multicolumn{7}{|l|}{ Socio-professional categories ${ }^{\mathrm{b}}$} \\
\hline $\mathrm{SPC}+$ & 192 & $(38.4)$ & 38 & $(19.8)$ & 1 & \\
\hline SPC- & 180 & $(36.1)$ & 29 & $(16.1)$ & $0.71[0.46-1.12]$ & 0.14 \\
\hline Inactive & 128 & $(25.5)$ & 50 & $(39.1)$ & $1.98[1.24-3.16]$ & 0.004 \\
\hline Pregnancy term ${ }^{c}$ & 23.5 & $(9.0)$ & 24 & $(8.9)$ & $1.00[0.98-1.02]$ & 0.84 \\
\hline \multicolumn{7}{|l|}{ Parity } \\
\hline Primiparous & 203 & $(40.6)$ & 48 & $(23.6)$ & 1 & \\
\hline Multiparous & 297 & $(59.4)$ & 69 & $(23.2)$ & $0.96[0.64-1.43]$ & 0.84 \\
\hline \multicolumn{7}{|c|}{ Level of perceived social support received during the lockdown } \\
\hline Very good & 180 & $(36)$ & 40 & $(22.2)$ & 1 & \\
\hline Good & 231 & $(46.1)$ & 48 & $(20.8)$ & $0.95[0.62-1.46]$ & 0.82 \\
\hline Little or none & 89 & $(17.9)$ & 29 & $(32.6)$ & $1.70[1.07-2.71]$ & 0.03 \\
\hline \multicolumn{7}{|c|}{ Serious disputes or violence during the lockdown } \\
\hline No & 360 & $(71.9)$ & 74 & $(20.6)$ & 1 & \\
\hline Yes & 140 & $(28.1)$ & 43 & $(30.7)$ & $1.47[1.00-2.16]$ & 0.05 \\
\hline \multicolumn{7}{|c|}{ Perceived general worry about the SARS-CoV-2 pandemic in France (max.10) ${ }^{d}$} \\
\hline Score less than or equal to 7 & 251 & $(51.7)$ & 67 & $(26.7)$ & 1 & \\
\hline Score above 7 & 234 & $(48.3)$ & 42 & $(17.9)$ & $0.66[0.46-0.96]$ & 0.03 \\
\hline \multicolumn{7}{|c|}{ Change in health professional for pregnancy monitoring during the lockdown } \\
\hline No & 426 & $(85.1)$ & 90 & $(21.1)$ & 1 & \\
\hline Yes & 74 & $(14.9)$ & 27 & $(36.5)$ & $1.57[1.04-2.36]$ & 0.03 \\
\hline
\end{tabular}

* Weighted and rounded values using Newton's algorithm [26] for discrete or qualitative variables. For continuous variables (age, pregnancy term), mean (standard deviation) were presented

** Adjusted Prevalence Ratio (aPR), Confidence Interval 95\% (95\% Cl) and p-value obtained with robust variance Poisson regression model

a Postponing/foregoing/not starting monitoring despite a gestational age of 15 weeks (see definition of the variable of interest in Methods section)

${ }^{b}$ Women on maternity leave and unemployed women were classified according to their current SPC category or their most recent category prior to ending work respectively

c At the end of the first lockdown (11/05/2020)

d 15 women did not document their worry score

pandemics. Despite the continued difficulties that countries around the world are still facing, this period provides an unprecedented opportunity for maternity units and hospitals to rethink their organisations and reinforce access to care for future health crises and ensure effective and efficient follow-up of pregnant women. One possible strategy - currently being discussed at the national level - is to coordinate all concerned professionals around a reference person [41].

\section{Abbreviations}

SARS-CoV-2: Severe acute respiratory syndrome coronavirus 2; COVID-19: Disease caused by SARS-CoV-2; MERS-CoV: Middle East respiratory syndromerelated coronavirus; SPC: Socio-professional category; PR: Prevalence Ratio; NPS: National Perinatal Survey.

\section{Supplementary Information}

The online version contains supplementary material available at https://doi. org/10.1186/s12884-021-04256-9.

Additional file 1. "Covimater - SARS-CoV-2 pandemic, first lockdown and pregnant women - Questionnaire". Objects offered to pregnant women during the first confinement in France in order to assess, among other things, their pregnancy monitoring.

\section{Acknowledgments}

We would like to thank Dorothée Lamarche (BVA Group) for her valuable help in developing the questionnaire and Jude Sweeney (Milan, Italy) for the English revision and editing of this manuscript.

\section{Authors' contributions}

A.D., L.A. and N.R. conceived of the presented idea. L.A. and A.D. developed the theory and performed the computations. N.R. verified the analytical 
methods. All authors discussed the results and contributed to the final manuscript. All authors read and approved the final manuscript.

\section{Funding}

This work was entirely financed by public funds.

\section{Availability of data and materials}

The datasets generated and/or analysed during the current study are not publicly available due privacy or ethical restrictions but are available from the corresponding author on reasonable request.

\section{Declarations}

\section{Ethics approval and consent to participate}

Covimater received approval from the Saint Maurice Hospital Ethics Committee on $01 / 07 / 2020$ (approval number $n^{\circ} 2020-1$ ) ensuring that all methods used in our study were carried out in accordance with the Declaration of Helsinki. Only pseudonymised databases were transmitted to Santé Publique France, guaranteeing the confidentiality of the information. We confirm that the Internet panel volunteers included in the Covimater study were informed of the purpose of the study at the time of their inclusion, and that they were free to participate or not in the survey. Informed consent was obtained from all participants. No subjects under 18 were included in the study.

\section{Consent for publication}

Only aggregated data is reported in this article. No personal information appears in this article.

\section{Competing interests}

The authors declare that they have no competing interests.

\section{Author details}

${ }^{1}$ Santé publique France, French national public health agency, Non-Communicable Diseases and Trauma Division, Perinatology, Early childhood and Mental Health Unit, 14, rue du Val d'Osne, F-94415 Saint-Maurice, France. ${ }^{2}$ Department of Gynecology and Obstetrics, Louis Mourier University Hospital, AP-HP, Colombes, France. ${ }^{3}$ Santé publique France, French national public health agency, Data processing, support and analysis department, Saint-Maurice, France. ${ }^{4}$ Santé publique France, French national public health agency, Alert and crisis department, Saint-Maurice, France. ${ }^{5}$ Santé Publique France, French national public health agency, Hauts-de-France regional office, Saint-Maurice, France. ${ }^{6}$ Division of Obstetrics and Gynecology, Antoine Béclère Hospital, AP-HP, Clamart, France. ${ }^{7}$ Paris Saclay University, Clamart, France.

Received: 8 June 2021 Accepted: 9 November 2021

Published online: 30 November 2021

\section{References}

1. Schwartz DA, Graham AL. Potential Maternal and Infant Outcomes from (Wuhan) Coronavirus 2019-nCoV Infecting Pregnant Women: Lessons from SARS, MERS, and Other Human Coronavirus Infections. Viruses. 2020;12(2):194. https://doi.org/10.3390/v12020194.

2. Rasmussen SA, Smulian JC, Lednicky JA, Wen TS, Jamieson DJ. Coronavirus Disease 2019 (COVID-19) and pregnancy: what obstetricians need to know. Am J Obstet Gynecol. 2020;222(5):415-26. https://doi.org/10. 1016/j.ajog.2020.02.017. Epub 2020 Feb 24. PMID: 32105680; PMCID: PMC7093856.

3. Poon LC, Yang H, Lee JCS, Copel JA, Leung TY, Zhang Y, Chen D, Prefumo F. ISUOG Interim Guidance on 2019 novel coronavirus infection during pregnancy and puerperium: information for healthcare professionals. Ultrasound Obstet Gynecol. 2020;55(5):700-8. https://doi.org/10.1002/ uog.22013. Epub 2020 Mar 20.

4. Peyronnet V, Sibiude J, Deruelle P, Huissoud C, Lescure X, Lucet JC, et al. Infection par le SARS-CoV-2 chez les femmes enceintes : état des connaissances et proposition de prise en charge par CNGOF. Gynécologie Obstétrique Fertil Sénologie. 2020;48(5):436-43.
5. Centers for Disease Control and Prevention. Covid-19 and pregnancy 2020. [Internet]. 2020. Available from: https://www.cdc.gov/coronavirus/ 2019-ncov/need-extra-precautions/pregnant-people.html. Accessed 3 Mar 2021.

6. Haut Conseil de la santé publique (HCSP). Actualisation de l'avis relatif aux personnes à risque de forme grave de Covid-19 et aux mesures barrières spécifiques à ces publics [Internet]. 2020. Available from: https:// www.hcsp.fr/explore.cgi/avisrapportsdomaine?clefr=807. Accessed 3 Mar 2021.

7. Public Health Agency of Canada. Coronavirus disease (covid-19) pregnancy, childbirth and caring for newborns: advice for mothers during covid-19. [Internet]. 2020. Available from: https://publications.gc.ca/site/ eng/9.885835/publication.html.

8. Public Health England (PHE). Guidance on social distancing for everyone in the UK. [Internet]. 2020. Available from: https://www.gov.uk/gover nment/publications/covid-19-guidance-on-social-distancing-and-forvulnerable-people/guidance-on-social-distancing-for-everyone-in-theuk-and-protecting-older-people-and-vulnerable-adults.

9. Federal Office of Public Health (FOPH). Coronavirus: People at especially high risk [Internet]. 2020. Available from: https://www.bag.admin.ch/bag/ en/home/krankheiten/ausbrueche-epidemien-pandemien/aktuelle-ausbr ueche-epidemien/novel-cov/krankheit-symptome-behandlung-ursprung/ besonders-gefaehrdete-menschen.html.

10. The American College of Obstetricians and Gynecologists. COVID-19 Obstetric Preparedness Manual. [Internet]. Washington; 2020. Available from: https://www.acog.org/-/media/project/acog/acogorg/files/pdfs/ education/covid-19-obstetric-preparedness-manual.pdf.

11. Royal College of Obstetricians and Gynaecologists, Royal College of Midwives. Guidance for antenatal and postnatal services in the evolving coronavirus (COVID-19) pandemic. London; 2020. Available from: https:// www.rcm.org.uk/media/3837/guidance-for-antenatal-and-postnatalservices-in-the-evolving-coronavirus-pandemic-rcm-and-rcog.pdf.

12. Vivanti AJ, Deruelle P, Picone O, Guillaume S, Roze JC, Mulin B, et al. Follow-up for pregnant women during the COVID-19 pandemic: French national authority for health recommendations. J Gynecol Obstet Hum Reprod. 2020;49(7):101804. https://doi.org/10.1016/j.jogoh.2020.101804.

13. Tschann M, Ly ES, Hilliard S, Lange HLH. Changes to medication abortion clinical practices in response to the COVID-19 pandemic. Contraception. 2021;104(1):77-81. https://doi.org/10.1016/j.contraception.2021.04.010.

14. Bradley D, Blaine A, Shah N, Mehrotra A, Gupta R, Wolfberg A. Patient experience of obstetric care during the COVID-19 pandemic: preliminary results from a recurring National Survey. J Patient Exp. 2020;7(5):653-6.

15. Jouen T, Gauthier T, Azais H, Bendifallah S, Chauvet P, Fernandez H, et al. The impact of the COVID-19 coronavirus pandemic on the surgical management of gynecological cancers: analysis of the multicenter database of the French SCGP and the FRANCOGYN group. J Gynecol Obstet Hum Reprod. 2021;50(8):102133.

16. Kayem G, Lecarpentier E, Deruelle P, Bretelle F, Azria E, Blanc J, et al. A snapshot of the Covid-19 pandemic among pregnant women in France. J Gynecol Obstet Hum Reprod. 2020;49:101826. https://doi.org/10.1016/j. jogoh.2020.101826.

17. Covid-19 and pregnancy. BMJ. 2020;369:m1672. https://www.bmj.com/ content/369/bmj.m1672.

18. Haute Autorité de Santé. Réponses rapides dans le cadre du COVID19-Téléconsultation et télésoin [Internet]. Available from: 2020. https:// www.has-sante.fr/jcms/p_3168867/fr/reponses-rapides-dans-le-cadredu-covid19-teleconsultation-et-telesoin.

19. Deneffe Dobrzyński ML. «Naissance en temps de Covid 19», Recherches \& éducations [Internet], HS | July 2020, Available from: http://journals.opene dition.org/rechercheseducations/11353, https://doi.org/10.4000/reche rcheseducations.11353.

20. Verweij EJ, M'hamdi HI, Steegers EAP, Reiss IKM, Schoenmakers S. Collateral damage of the covid-19 pandemic: a Dutch perinatal perspective. BMJ. 2020;369:m2326. https://doi.org/10.1136/bmj.m2326.

21. Haute Autorité de Santé. Suivi et orientation des femmes enceintes en fonction des situations à risque identifiées [Internet]. 2016. Available from: https://www.has-sante.fr/jcms/c_547976/fr/suivi-et-orientationdes-femmes-enceintes-en-fonction-des-situations-a-risque-identifiees. 
22. Ferrara A, Hedderson MM, Brown SD, Ehrlich SF, Tsai A-L, Feng J, et al. A telehealth lifestyle intervention to reduce excess gestational weight gain in pregnant women with overweight or obesity (GLOW): a randomised, parallel-group, controlled trial. Lancet Diabetes Endocrinol. 2020;8(6):490-500.

23. Goldstein RF, Abell SK, Ranasinha S, Misso M, Boyle JA, Black MH, et al. Association of gestational weight gain with maternal and infant outcomes: a systematic review and Meta-analysis. JAMA. 2017:317(21):2207-25.

24. Crowther CA, Hiller JE, Moss JR, McPhee AJ, Jeffries WS, Robinson JS et al. Effect of treatment of gestational diabetes mellitus on pregnancy outcomes. N Engl J Med. 2005;352(24):2477-86. https://doi.org/10.1056/ NEJMoa042973.

25. French National Institute of Statistics and Economic Studies [Internet]. Available from: https://www.insee.fr/en/information/2107702.

26. Deville JC, Särndal CE. Calibration Estimators in Survey Sampling. J Am Stat Assoc. 1992;87(418):376-82.

27. Piffaretti C, Looten V, Rey S, Fresson J, Fagot-Campagna A, Tuppin P. Management of pregnancy based on healthcare consumption of women who delivered in France in 2015: contribution of the national health data system (SNDS). J Gynecol Obstet Hum Reprod. 2018;47(7):299-307.

28. Ministry of Health. Coronavirus COVID-19: Carte du déconfinement en France [Internet]. 2020. Available from: https://www.cascoronavirus.fr/ carte-deconfinement/france.

29. Barros AJD, Hirakata VN. Alternatives for logistic regression in cross-sectional studies: an empirical comparison of models that directly estimate the prevalence ratio. BMC Med Res Methodol. 2003;3(1):21.

30. Zou G. A modified poisson regression approach to prospective studies with binary data. Am J Epidemiol. 2004;159(7):702-6.

31. Raude J, Lecrique J-M, Lasbeur L, Leon C, Guignard R, du Roscoät E, et al. Determinants of preventive behaviors in response to the COVID-19 pandemic in France: comparing the sociocultural, Psychosocial, and Social Cognitive Explanations Front Psychol 2020;11. Available from: https:// www.frontiersin.org/articles/10.3389/fpsyg.2020.584500/full.

32. Campbell J, García-Moreno C, Sharps P. Abuse during pregnancy in industrialized and developing countries. Violence Women. 2004;10(7):770-89.

33. National Institute of Justice. Findings About Partner Violence From the Dunedin Multidisciplinary Health and Development Study, Research in Brief [Internet]. 1999. Available from: https://www.ojp.gov/pdffiles1/ 170018.pdf.

34. Stöckl H, Watts C, Kilonzo Mbwambo JK. Physical violence by a partner during pregnancy in Tanzania: prevalence and risk factors. Reprod Health Matters. 2010;18(36):171-80.

35. Hill A, Pallitto C, McCleary-Sills J, Garcia-Moreno C. A systematic review and meta-analysis of intimate partner violence during pregnancy and selected birth outcomes. Int J Gynaecol Obstet Off Organ Int Fed Gynaecol Obstet. 2016;133(3):269-76.

36. Silverman JG, Decker MR, Reed E, Raj A. Intimate partner violence victimization prior to and during pregnancy among women residing in 26 U.S. states: associations with maternal and neonatal health. Am J Obstet Gynecol. 2006;195(1):140-8.

37. Sigalla GN, Mushi D, Meyrowitsch DW, Manongi R, Rogathi JJ, Gammeltoft $\mathrm{T}$, et al. Intimate partner violence during pregnancy and its association with preterm birth and low birth weight in Tanzania: a prospective cohort study. PLoS One. 2017;12(2):e0172540.

38. Ancelot $L$, Bonnal $L$, Depret M. Déterminants du renoncement aux soins des femmes durant leur grossesse. (2016). Revue française d'économie, XXXI, 63-107. https://doi.org/10.3917/rfe.164.0063.

39. Javanmardi M, Noroozi M, Mostafavi F, Ashrafi-rizi H. Internet usage among pregnant women for seeking health information: a review article. Iran J Nurs Midwifery Res. 2018;23(2):79-86.

40. LOI n² 2002-303 du 4 mars 2002 relative aux droits des malades et à la qualité du système de santé (1) - Légifrance [Internet]. Available from: https://www.legifrance.gouv.fr/jorf/id/JORFTEXT000000227015/.

41. Ministry of Health. Les 1000 premiers jours: Là où tout commence. [Internet]. 2020. Available from: https://solidarites-sante.gouv.fr/IMG/pdf/rappo rt-1000-premiers-jours.pdf.

\section{Publisher's Note}

Springer Nature remains neutral with regard to jurisdictional claims in published maps and institutional affiliations.
Ready to submit your research? Choose BMC and benefit from:

- fast, convenient online submission

- thorough peer review by experienced researchers in your field

- rapid publication on acceptance

- support for research data, including large and complex data types

- gold Open Access which fosters wider collaboration and increased citations

- maximum visibility for your research: over $100 \mathrm{M}$ website views per year

At BMC, research is always in progress.

Learn more biomedcentral.com/submissions 